\title{
Cyclopolymerization of Isopropenyl Acrylate and Methacrylate
}

\author{
Wakichi FuKUDA, Hozumi SATO, Toshikazu IMAI, \\ and Hiroshi KAKIUCHI

\begin{abstract}
Department of Applied Chemistry, Faculty of Engineering, Yokohama National University,
\end{abstract} \\ Tokiwadai, Hodogaya-ku, Yokohama 240, Japan
}

(Received January 27, 1986)

\begin{abstract}
Radical polymerization of isopropenyl acrylate (IPA) and methacrylate (IPMA) was investigated at $60^{\circ} \mathrm{C}$ in benzene. The residual double bond in the polymers was determined to be mainly isopropenyl groups by spectroscopy and titrimetry. The decrease in the residual double bonds of polymers with decreasing initial monomer concentration can be explained in terms of an intramolecular chain monocyclization-bicyclization mechanism, in which the monocyclization took place between a growing polymer radical and the isopropenyl group of the penultimate monomer unit, and the bicyclization, between a monocyclized radical and the isopropenyl group of the terminal unit. The ratios of rate constants for the reactions of monocyclization and bicyclization over intermolecular propagation were evaluated to be 5.0 and $0.13 \mathrm{moldm}^{-3}$ for IPA and 0.26 and $0.06 \mathrm{~mol} \mathrm{dm}^{-3}$ for IPMA, respectively. The effect of temperature on the overall rate of polymerization of IPA and on the amount of residual double bonds of poly(IPA) was examined. Copolymerization of styrene with these monomers gave apparent monomer reactivity ratios; $r_{1}(\mathrm{St})=0.23, r_{2}(\mathrm{IPA})=0.79$ and $r_{1}(\mathrm{St})=0.35, r_{2}$ (IPMA) $=0.60$.

KEY WORDS Cyclopolymerization / Monocyclization / Bicyclization / Isopropenyl Acrylate / Isopropenyl Methacrylate / Copolymerization / Monomer Reactivity Ratio /
\end{abstract}

Although cyclopolymerizations of vinyl $\beta$ substituted acrylates ${ }^{1-4}$ and isopropenyl ethyl maleate $^{5}$ as unsymmetrical 1,5-dienes were conducted to lead to the formation of polymers containing $\gamma$-lactone or/and $\beta$-lactone units along the main chain, those of vinyl acrylate (VA), methacrylate (VMA), and $\alpha$ chloroacrylate (VCA) gave the polymers containing $\delta$-lactone or larger cyclic units. ${ }^{6,7}$ The mechanism of cyclopolymerization of VA, VMA, and VCA has been studied. ${ }^{7}$ The suggested propagation reactions are intermolecular addition of a polymer radical to the acryl or $\alpha$-substituted acryl group of monomers, intramolecular monocyclization of a polymer radical with the vinyl group of a penultimate monomer unit, and intramolecular bicyclization of a monocyclized rad- ical with the vinyl group of a polymer end. The effect of the $\alpha$-substituent of acryl residues on the degree of cyclization was evident in the monocyclization tendency which decreased with increasing size of the $\alpha$-substituent of acryl residues.

In this article, cyclopolymerizations of isopropenyl acrylate (IPA) and methacrylate (IPMA) are described in order to evaluate the effect of $\alpha$-methyl substituent of the vinyl residue on the intramolecular cyclization reactions. The effect of temperature on the degree of cyclization of poly(IPA) was examined. In addition, copolymerization of styrene with IPA and IPMA was carried out to see which olefinic group of dienes would participate in the intermolecular propagation. 


\section{EXPERIMENTAL}

\section{Monomers}

The monomers were prepared by reactions of chloromercurio acetone with acyl chlorides. Chloromercurio acetone was prepared by the method of Nesmeyanov et al. ${ }^{8}$; yield $87 \%$; mp $103.3-104.5^{\circ} \mathrm{C}$. Acryloyl and methacryloyl chlorides were prepared by the reaction of respective acids with benzoyl chloride.

Isopropenyl Acrylate (IPA). Chloromercurio acetone $(0.146 \mathrm{~mol})$ and hydroquinone $(0.5 \mathrm{~g})$ were dissolved in tetralin (150 $\mathrm{cm}^{3}$ ). To this solution was added acryloyl chloride $(0.146 \mathrm{~mol})$ at $40^{\circ} \mathrm{C}$ with stirring. The reaction was carried out for $6 \mathrm{~h}$ at $70^{\circ} \mathrm{C}$. A small amount of quinoline was added to the reaction mixture and mercury(II) salt was separated on a suction funnel. Redistillation of a low boiling fraction gave IPA; yield $82 \%$; bp $55.0-56.2^{\circ} \mathrm{C} / 80 \mathrm{mmHg}(1 \mathrm{mmHg}=$ $133.322 \mathrm{~Pa}$ ); $n_{\mathrm{D}}^{25} 1.4283 ; d_{4}^{25} 0.9241$; IR (benzene) $1730(\mathrm{C}=\mathrm{O}$ ), 1670 (isopropenyl $\mathrm{C}=\mathrm{C}$ ), 1635 (acryl $\mathrm{C}=\mathrm{C}), 985$ (acryl $\mathrm{C}=\mathrm{C}-\mathrm{H})$, and $870 \mathrm{~cm}^{-1}$ (isopropenyl $\mathrm{C}=\mathrm{C}-\mathrm{H}$ ); ${ }^{1} \mathrm{H}$ NMR (neat) $\delta=6.38\left(\mathrm{~m}, 1 \mathrm{H}, \mathrm{CH}_{2}=\mathrm{C} \underline{\mathrm{H}}-\mathrm{C}=\mathrm{O}\right), 6.23$ $\left(\mathrm{m}, 1 \mathrm{H}\right.$, cis $\left.-\mathrm{CH}_{2}=\mathrm{CH}-\mathrm{C}=\mathrm{O}\right), 5.92(\mathrm{~m}, 1 \mathrm{H}$, trans $\left.-\mathrm{C}_{2}=\mathrm{CH}-\mathrm{C}=\mathrm{O}\right), 4.73\left(\mathrm{~d}, 2 \mathrm{H}, \mathrm{C}_{2}=\right.$ $\mathrm{C}-\mathrm{O})$, and $1.94 \mathrm{ppm}\left(\mathrm{s}, 3 \mathrm{H}, \mathrm{CH}_{3}\right)$.

Isopropenyl Methacrylate (IPMA). The reaction of chloromercurio acetone with methacryloyl chloride similarly gave IPMA; yield $93 \% ;$ bp $56.9^{\circ} \mathrm{C} / 49 \mathrm{mmHg} ; n_{\mathrm{D}}^{25} 1.4315 ; d_{4}^{25}$ 0.9242; IR $\left(\mathrm{CHCl}_{3}\right) 1725(\mathrm{C}=\mathrm{O}), 1670$ (isopropenyl $\mathrm{C}=\mathrm{C}$ ), 1640 (methacryl $\mathrm{C}=\mathrm{C}$ ), 940 (methacryl $\mathrm{C}=\mathrm{C}-\mathrm{H}$ ), and $875 \mathrm{~cm}^{-1}$ (isopropenyl $\mathrm{C}=\mathrm{C}-\mathrm{H}) ;{ }^{1} \mathrm{H}$ NMR (neat) $\delta=6.10(\mathrm{t}$, $1 \mathrm{H}$, cis $\left.-\mathrm{CH}_{2}=\mathrm{C}-\mathrm{C}=\mathrm{O}\right), 5.69(\mathrm{t}, 1 \mathrm{H}$, trans $\left.\mathrm{CH}_{2}=\mathrm{C}-\mathrm{C}=\mathrm{O}\right), 4.65$ (s, 2H, $\left.\underline{\mathrm{H}}_{2}=\mathrm{C}-\mathrm{O}\right)$, and $1.92 \mathrm{ppm}\left(\mathrm{s}, 6 \mathrm{H}, \mathrm{CH}_{3}\right)$.

The monomers were distilled prior to use and their purity was determined by GLC on diethyleneglycol succinate. They contained only acetone as an impurity less than $1 \%$. Elemental analyses of monomers gave lower carbon content than the calculated value be- cause of their high volatility.

Styrene, $\alpha, \alpha^{\prime}$-azobisisobutyronitrile (AIBN) and solvents were commercial products which were purified by usual methods. The other reagents were used as received. Butyl lithium was supplied as a $15.2 \mathrm{wt} \%$ solution in hexane and sodium bis(trimethylsilyl)amide was supplied as a $0.227 \mathrm{~mol} \mathrm{dm}^{-3}$ solution in toluene.

\section{Radical Polymerization and Copolymeriza- tion}

These processes were carried out in a sealed glass tube with shaking in an incubator. Polymers were separated by pouring the reaction mixture into methanol and dried in vacuo.

Anal. Calcd for poly(IPA) $\mathrm{C}_{6} \mathrm{H}_{8} \mathrm{O}_{2}:$ C, $64.27 \%$; H, 7.19\%. Found: C, $64.21 \%$; $7.49 \%$. Calcd for poly(IPMA) $\mathrm{C}_{7} \mathrm{H}_{10} \mathrm{O}_{2}$ : C, $66.64 \%$; H, $7.99 \%$. Found: C, $66.62 \%$, H, $8.37 \%$.

The elemental analyses of copolymers gave their compositions.

Poly(St-co-IPA) containing $65 \%$ of styrene: IR (film) $1740(\mathrm{C}=\mathrm{O}), 1665$ (isopropenyl $\mathrm{C}=\mathrm{C}$ ), and $685 \mathrm{~cm}^{-1}$ (phenyl); ${ }^{1} \mathrm{H}$ NMR $\left(\mathrm{CCl}_{4}\right) \delta=7.03,6.70$ (broad, 5H, phenyl $\underline{\mathrm{H}}$ ), 4.46 (broad, $0.92 \mathrm{H}, \mathrm{CH}_{2}=\mathrm{C}-\mathrm{O}$ ), and 1.66 ppm (m, 6.46H, $\left.\mathrm{CH}, \mathrm{CH}_{2}, \mathrm{CH}_{3}\right)$.

Poly(St-co-IPMA) containing $30 \%$ of styrene: IR (film) $1740(\mathrm{C}=\mathrm{O})$ and $1670 \mathrm{~cm}^{-1}$ (isopropenyl $\mathrm{C}=\mathrm{C}$ ); ${ }^{1} \mathrm{H}$ NMR $\left(\mathrm{CCl}_{4}\right) \delta=$ 7.02 (broad, 5H, phenyl $\underline{\mathrm{H}}$ ), 4.57 (broad, $\left.3.67 \mathrm{H}, \mathrm{CH}_{2}=\mathrm{C}-\mathrm{O}\right), 1.87$ and $1.62 \mathrm{ppm}$ (d and broad, $20.57 \mathrm{H}, \mathrm{CH}, \mathrm{CH}_{2}, \mathrm{CH}_{3}$ ).

\section{Anionic Polymerization}

Polymerization was carried out at $-78^{\circ} \mathrm{C}$ under a nitrogen atmosphere in a glass tube with intermittent shaking. Calcium hydride was used as a dehydrating agent for monomers and solvent. The catalyst solution was added using a hypodermic syringe through a neoprene rubber stopper. The polymerization was stopped by addition of a small amount of methanol. The polymer was separated and 
dried in vacuo. Poly(IPA): IR (film) 1746 (C= O), 1674 (isopropenyl $\mathrm{C}=\mathrm{C}$ ), and $870 \mathrm{~cm}^{-1}$ (isopropenyl $\mathrm{C}=\mathrm{C}-\mathrm{H}) ;{ }^{1} \mathrm{H}$ NMR $\left(\mathrm{CDCl}_{3}\right)$ $\delta=4.66$ (s, 2H, $\left.\mathrm{CH}_{2}=\mathrm{C}-\mathrm{O}\right), 2.45$ (broad, $1 \mathrm{H}, \mathrm{C} \underline{\mathrm{H}}$ ), and $1.92 \mathrm{ppm}$ (s and broad, $5 \mathrm{H}, \mathrm{CH}_{3}$ and $\left.\mathrm{CH}_{2}\right)$. Poly(IPMA): IR (film) $1740(\mathrm{C}=$ O), 1670 (isopropenyl $\mathrm{C}=\mathrm{C}$ ), and $870 \mathrm{~cm}^{-1}$ (isopropenyl $\mathrm{C}=\mathrm{C}-\mathrm{H}$ ).

\section{Analyses}

The residual double bond $\left(f_{\mathrm{u}}\right)$ in the polymer was determined by the ICl titrimetric method where the reaction was carried out for $1 \mathrm{~h}$ in a chloroform solution. The bromidebromate titrimetric method was applied for poly(IPA) and gave almost the same values of $f_{\mathrm{u}}$ determined by the $\mathrm{ICl}$ titrimetric method. The ${ }^{1} \mathrm{H}$ NMR spectrum of poly(IPA) prepared at $0.13 \mathrm{~mol} \mathrm{dm}^{-3}$ of monomer concentration showed broad signals at $\delta=4.60,1.88$ and $1.20 \mathrm{ppm}$ but no signal at $6.4-5.9 \mathrm{ppm}$ for acryl protons. The ${ }^{1} \mathrm{H}$ NMR spectrum of

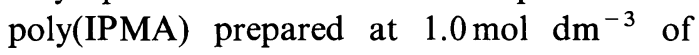
monomer concentration showed signals at $\delta=4.65,1.90$ and $1.10 \mathrm{ppm}$ but no signal for methacryl protons.

IR spectra were recorded on a Hitachi EPI2 spectrometer and ${ }^{1} \mathrm{H}$ NMR spectra on a JEOL-JNM C-60-H spectrometer with tetramethylsilane as an internal reference.

\section{RESULTS AND DISCUSSION}

\section{Radical Polymerization}

Both IPA and IPMA were polymerized using AIBN as the initiator in benzene at $60^{\circ} \mathrm{C}$. The soluble polymers were obtained at conversion lower than $30 \%$ in the polymerization at $1.0 \mathrm{~mol} \mathrm{dm} \mathrm{dm}^{-3}$ of monomer concentration. Figure 1 shows the effects of initial monomer concentration $[\mathrm{M}]_{0}$ and initiator concentration $[\mathrm{AIBN}]_{0}$ on the overall rate of polymerization, $R_{\mathrm{p}}$. They gave the following relationships.

$$
R_{\mathrm{p}} \propto[\mathrm{IPA}]_{0}^{1.44}[\mathrm{AIBN}]_{0}^{0.56}
$$

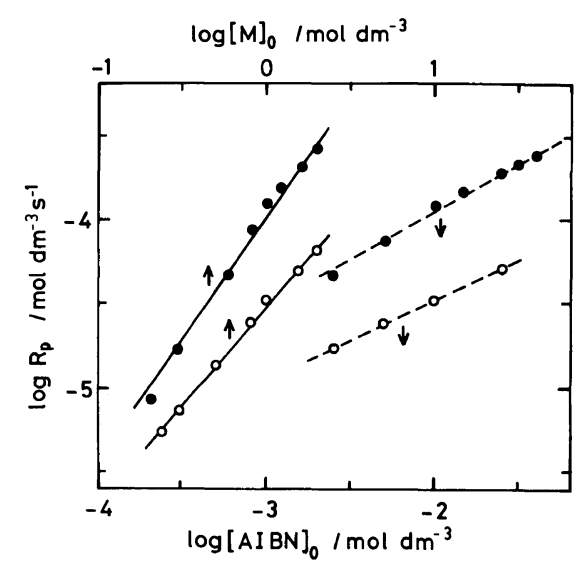

Figure 1. Effects of initial monomer concentration $[\mathrm{M}]_{0}$ and initiator concentration $[\mathrm{AIBN}]_{0}$ on the overall rate of polymerization $R_{\mathrm{p}}$ in benzene at $60^{\circ} \mathrm{C}$ : $\bigcirc$, IPA; O, IPMA.

$$
R_{\mathrm{p}} \propto[\mathrm{IPMA}]_{0}^{1.12}[\mathrm{AIBN}]_{0}^{0.49}
$$

Kinetics are almost normal in the polymerization of IPMA, while a high dependency on the monomer concentration is observed in the polymerization of IPA. The rate of polymerization of IPMA is almost the same as that of methyl methacrylate (MMA), ${ }^{9}$ while that of IPA is lower by one third as compared to that of methyl acrylate (MA). ${ }^{9}$ Since the monomer reactivity ratios of MMA and isopropenyl acetate are 30 and $0.017^{10}$ (23.6 and 0.095 calculated from $Q$ and $e$ values), intermolecular propagation of IPMA will proceed mainly between a polymer radical and methacryl group. The monomer reactivity ratios of MA and isopropenyl acetate were calculated to be 18.1 and 0.186 from their $Q$ and $e$ values. ${ }^{10}$ Accordingly, intermolecular propagation of IPA will proceed mainly between a polymer radical and acryl group, and partly between a polymer radical and isopropenyl group. This may be one reason why the rate of polymerization of IPA is lower than that of MA. Other reasons suggested are intramolecular cyclization of a polymer radical with a pendent isopropenyl group of polymer and cross-termination between growing polymer radicals of acryl and 
isopropenyl residues. The isopropenyl group of IPA monomer takes part in the polymerization process.

\section{Characterization of Polymers}

In order to characterize the chemical structures of poly(IPA) and poly(IPMA), the anionic polymerization of IPA and IPMA was carried out at $-78^{\circ} \mathrm{C}$ in toluene. The anionic poly(IPA) prepared by BuLi contained less isopropenyl groups than the calculated value, while the polymer prepared by $\left(\mathrm{Me}_{3} \mathrm{Si}\right)_{2} \mathrm{NNa}$ had the expected isopropenyl group content. Absorption peaks in both spectra of IR and ${ }^{1} \mathrm{H}$ NMR of poly(IPA) confirmed these structures. Similarly, the anionic poly(IPMA) was characterized as containing isopropenyl groups but no methacryl groups by both IR and ${ }^{1} \mathrm{H}$ NMR spectra. Table I shows the results of anionic polymerization.

Figure 2 shows some of the IR spectra of polymers. In the IR spectrum of radical poly(IPA), an absorption peak for carbonyl group at $1730 \mathrm{~cm}^{-1}$ is broad and of a lower wave number than that of anionic poly(IPA). The residual double bond in the radical poly(IPA) is assigned to isopropenyl group from the absorption peak at $1670 \mathrm{~cm}^{-1}$. The IR spectrum of radical poly(IPMA) is almost identical with that of anionic poly(IPMA) with a little difference in the absorption peak of carbonyl group. No peak of methacryl protons can be observed in either the ${ }^{1} \mathrm{H}$ NMR spectra of radical or anionic poly(IPMA). Therefore, the chemical structure of the radical poly(IPMA) is almost the same as that of the anionic poly(IPMA).

\section{Cyclopolymerization Mechanism}

Table II shows the effect of monomer concentration on the amount of residual double bonds $\left(f_{\mathrm{u}}\right)$ of the polymers. A decrease in $f_{\mathrm{u}}$ with decreasing monomer concentration was observed in both polymers of IPA and IPMA. When intermolecular propaga-
Table I. Anionic polymerization of IPA and IPMA in toluene at $-78^{\circ} \mathrm{C}$

\begin{tabular}{|c|c|c|c|c|c|c|}
\hline \multirow{2}{*}{$\frac{\text { Monomer }}{\mathrm{cm}^{3}}$} & \multirow{2}{*}{$\frac{\text { Solvent }}{\mathrm{cm}^{3}}$} & \multirow{2}{*}{\multicolumn{2}{|c|}{$\frac{\text { Initiator }^{\mathrm{a}}}{\mathrm{cm}^{3}}$}} & \multirow{2}{*}{$\frac{\text { Time }}{\mathrm{h}}$} & \multirow{2}{*}{$\frac{\text { Yield }}{\%}$} & \multirow{2}{*}{$f_{\mathrm{u}}^{\mathrm{b}}$} \\
\hline & & & & & & \\
\hline \multicolumn{7}{|l|}{ IPA } \\
\hline 0.98 & 8.05 & A & 0.50 & 12 & 16.5 & 0.83 \\
\hline 0.95 & 7.86 & A & 0.50 & 13.5 & $31.9^{c}$ & 0.77 \\
\hline 1.50 & 5.00 & B & 0.50 & 3 & 6.2 & 1.06 \\
\hline 1.50 & 5.00 & B & 0.47 & 20 & $6.9^{\mathrm{d}}$ & 1.02 \\
\hline \multicolumn{7}{|l|}{ IPMA } \\
\hline 1.50 & 9.00 & A & 1.00 & 20 & 8.9 & - \\
\hline 0.80 & 4.50 & A & 1.00 & 17 & 12.2 & $0.93^{\mathrm{e}}$ \\
\hline
\end{tabular}

a A was a $15.2 \mathrm{wt} \% \mathrm{BuLi}$ solution in hexane and $\mathrm{B}$ was a $0.277 \mathrm{~mol} \mathrm{dm}^{-3}\left[\mathrm{Me}_{3} \mathrm{Si}\right]_{2} \mathrm{NNa}$ solution in toluene.

b Mole fraction of isopropenyl group per monomer unit determined by $\mathrm{ICl}$ titrimetry.

c,d $\eta_{\mathrm{sp}} / c$ were 0.41 and $0.39 \mathrm{dlg}^{-1}$ in benzene at $25^{\circ} \mathrm{C}, c$, $0.25-0.30 \mathrm{~g} \mathrm{dl}^{-1}$.

e Determined by ${ }^{1} \mathrm{H}$ NMR spectroscopy.

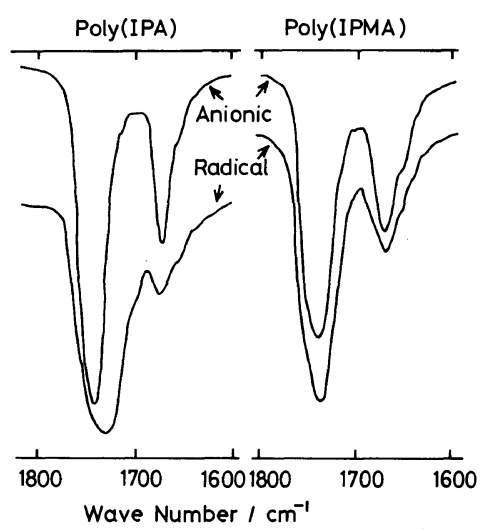

Figure 2. Infrared spectra of polymer films: anionic poly(IPA) prepared by $\left(\mathrm{Me}_{3} \mathrm{Si}\right)_{2} \mathrm{NNa}$; radical poly(IPA) prepared at [IPA $]_{0}, 0.13 \mathrm{~mol} \mathrm{dm}^{-3}$; anionic poly(IPMA) prepared by $\mathrm{BuLi}$; radical poly(IPMA) prepared at $[\mathrm{IPMA}]_{0}, 1.0 \mathrm{~mol} \mathrm{dm}^{-3}$.

tion takes place between a growing polymer radical and acryl or methacryl group of monomers along with intramolecular cyclization between a growing polymer radical and a pendent isopropenyl group of a polymer end, the equation derived by Roovers and Smets ${ }^{1}$ can be used: 


$$
\frac{1}{f_{\mathrm{c}}}=1+\frac{[\mathrm{M}]_{0}}{r_{\mathrm{c}}}
$$

where $f_{\mathrm{c}}=1-f_{\mathrm{u}}, r_{\mathrm{c}}$ is the ratio of rate constants of intramolecular cyclization over intermolecular propagation and $[\mathrm{M}]_{0}$ is the initial monomer concentration. The plots of $1 / f_{\mathrm{c}}$ vs. $[\mathrm{M}]_{0}$ give straight lines but intercepts of the lines are 1.37 for poly(IPA) and 2.37 for poly(IPMA), respectively. Deviation of intercepts from eq 1 and the absence of $\gamma$ lactone units judged from the IR spectra of polymers suggest that cyclization at a growing polymer end is improbable.

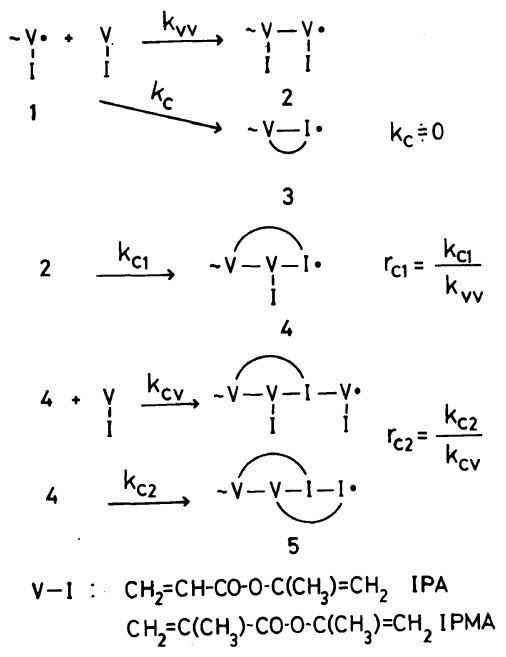

When intramolecular cyclization takes place between a growing polymer radical and the pendent isopropenyl group of a penultimate monomer unit and then that between a monocyclized radical and the isopropenyl group of a terminal monomer unit, eq 2 is introduced by the procedure of a former paper. ${ }^{7}$

$$
f_{\mathrm{u}}=\frac{[\mathrm{M}]_{0}^{2}+\left(r_{\mathrm{c} 1}+r_{\mathrm{c} 2}\right)[\mathrm{M}]_{0}}{[\mathrm{M}]_{0}^{2}+\left(2 r_{\mathrm{c} 1}+r_{\mathrm{c} 2}\right)[\mathrm{M}]_{0}+2 r_{\mathrm{c} 1} r_{\mathrm{c} 2}}
$$

where $r_{\mathrm{c} 1}$ and $r_{\mathrm{c} 2}$ are the ratios of rate constants of intramolecular monocyclization and bicyclization over intermolecular propagation, respectively. When $r_{\mathrm{c} 1} \gg r_{\mathrm{c} 2}$ and the monomer concentration is low, eq 3 is intro-

\begin{tabular}{|c|c|c|c|c|c|}
\hline \multirow{2}{*}{$\begin{array}{l}\text { Mono- } \\
\text { mer }\end{array}$} & \multirow{2}{*}{$\frac{[\mathrm{M}]_{0}}{\mathrm{moldm}}$} & \multirow{2}{*}{ Time } & \multirow{2}{*}{$\frac{\text { Conversion }}{\%}$} & \multirow{2}{*}{$f_{\mathrm{u}}^{\mathrm{b}}$} & \multirow{2}{*}{$\frac{\eta_{\mathrm{sp}} / c^{\mathrm{c}}}{\mathrm{dl} \mathrm{g}^{-1}}$} \\
\hline & & & & & \\
\hline \multirow[t]{10}{*}{ IPA } & 0.13 & 100 & 5.6 & 0.30 & - \\
\hline & 0.21 & 60 & 9.5 & 0.33 & - \\
\hline & 0.31 & 50 & 13.5 & 0.37 & 0.08 \\
\hline & 0.60 & 30 & 14.4 & 0.43 & 0.09 \\
\hline & 0.80 & 20 & 13.0 & 0.45 & 0.09 \\
\hline & 1.00 & 20 & 15.0 & 0.50 & 0.09 \\
\hline & 1.20 & 15 & 11.6 & 0.52 & 0.11 \\
\hline & 1.60 & 12 & 9.2 & 0.55 & 0.15 \\
\hline & 2.00 & 5 & 4.0 & 0.61 & 0.30 \\
\hline & 3.02 & 4 & 21.0 & & gel \\
\hline \multirow[t]{7}{*}{ IPMA } & 0.30 & 76 & 10.9 & 0.72 & 0.09 \\
\hline & 0.50 & 76 & 12.3 & 0.74 & 0.12 \\
\hline & 0.80 & 66 & 12.2 & 0.79 & 0.21 \\
\hline & 1.00 & 40 & 8.0 & $\begin{array}{c}0.84 \\
\left(0.87^{\mathrm{d}}\right)\end{array}$ & 0.26 \\
\hline & 1.50 & 30 & 5.9 & 0.87 & 0.35 \\
\hline & 2.00 & 60 & 13.4 & 0.88 & 0.38 \\
\hline & 2.40 & 63 & 12.6 & 0.91 & 0.50 \\
\hline \multicolumn{6}{|c|}{$\begin{array}{l}\text { In benzene at } 60^{\circ} \mathrm{C} ;[\mathrm{AIBN}]_{0} \text {, } \\
\text { mol dm }{ }^{-3} \text {. }\end{array}$} \\
\hline \multicolumn{6}{|c|}{$\begin{array}{l}\text { b Mole fraction of residual isopropenyl groups per } \\
\text { monomer unit determined by } \mathrm{ICl} \text { titrimetry. } \\
\text { c Determined in benzene at } 25^{\circ} \mathrm{C} ; c, 0.25-0.30 \mathrm{~g} \mathrm{dl}^{-1} \text {. } \\
\text { d Determined by }{ }^{1} \mathrm{H} \text { NMR spectroscopy. }\end{array}$} \\
\hline
\end{tabular}

Table I. Radical polymerization of IPA and IPMA ${ }^{\mathrm{a}}$

duced from eq 2 .

$$
\frac{[\mathrm{M}]_{0}}{2 f_{\mathrm{u}}}=[\mathrm{M}]_{0}+r_{\mathrm{c} 2}
$$

The plot of $[\mathrm{M}]_{0} / 2 f_{\mathrm{u}} v s .[\mathrm{M}]_{0}$ for poly(IPA) gives a straight line with a slope of 1.0 and an intercept of $0.10 \mathrm{~mol} \mathrm{dm}^{-3}$ which is the $r_{\mathrm{c} 2}$ value. On the other hand, the plot of $[\mathrm{M}]_{0} / 2 f_{\mathrm{u}}$ vs. $[\mathrm{M}]_{0}$ for poly(IPMA) gives a straight line having a slope of 0.54 , which suggests that the assumption of $r_{\mathrm{c} 1} \gg r_{\mathrm{c} 2}$ is not applicable to poly(IPMA).

A computer simulation of eq 2 gives the most probable parameters for both poly(IPA) and poly(IPMA). Figure 3 shows the plots of $f_{\mathrm{u}}$ vs. $[\mathrm{M}]_{0}$ along with theoretical curves of eq 2 where $r_{\mathrm{c} 1}$ and $f_{\mathrm{c} 2}$ are 5.0 and $0.13 \mathrm{~mol} \mathrm{dm}^{-3}$ for poly(IPA) and 0.26 and $0.06 \mathrm{~mol} \mathrm{dm}^{-3}$ for poly(IPMA). In conclu- 


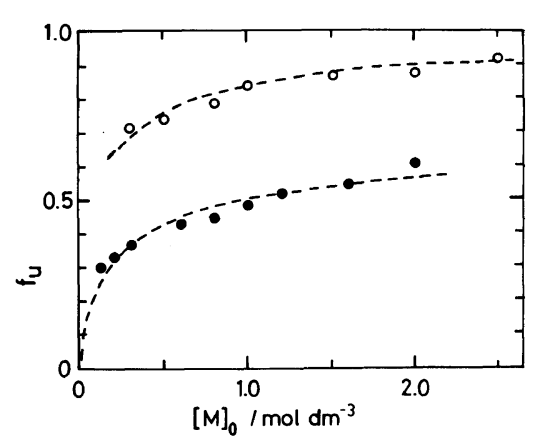

Figure 3. Effects of initial monomer concentration $[\mathrm{M}]_{0}$ on the fraction of residual isopropenyl groups per monomer unit, $f_{\mathrm{u}}$ : broken curves are obtained from eq 2 ; O, IPA, $r_{\mathrm{c} 1} 5.0$ and $r_{\mathrm{c} 2} 0.13 \mathrm{moldm}^{-3} ; 0$, IPMA, $r_{\mathrm{c} 1}$ 0.26 and $r_{\mathrm{c} 2} 0.06 \mathrm{~mol} \mathrm{dm}^{-3}$.

Table III. Cyclization constants

\begin{tabular}{|c|c|c|c|}
\hline & Monomer & $r_{\mathrm{c} 1}{ }^{\mathrm{b}}$ & $r_{\mathrm{c} 2}^{\mathrm{c}}$ \\
\hline $\mathrm{VA}^{\mathrm{a}}$ & $\mathrm{CH}_{2}=\mathrm{CH}-\mathrm{CO}-\mathrm{O}-\mathrm{CH}=\mathrm{CH}_{2}$ & 20 & 0.10 \\
\hline $\mathrm{VCA}^{\mathrm{a}}$ & $\mathrm{CH}_{2}=\mathrm{C}(\mathrm{Cl})-\mathrm{CO}-\mathrm{O}-\mathrm{CH}=\mathrm{CH}_{2}$ & 0.60 & 0.10 \\
\hline VMA $^{a}$ & $\mathrm{CH}_{2}=\mathrm{C}\left(\mathrm{CH}_{3}\right)-\mathrm{CO}-\mathrm{O}-\mathrm{CH}=\mathrm{CH}_{2}$ & 0.22 & 0.10 \\
\hline IPA & $\mathrm{CH}_{2}=\mathrm{CH}-\mathrm{CO}-\mathrm{O}-\mathrm{C}\left(\mathrm{CH}_{3}\right)=\mathrm{CH}_{2}$ & 5.0 & 0.13 \\
\hline IPMA & $\begin{array}{l}\mathrm{CH}_{2}=\mathrm{C}\left(\mathrm{CH}_{3}\right)-\mathrm{CO}-\mathrm{O}-\mathrm{C}\left(\mathrm{CH}_{3}\right) \\
\quad=\mathrm{CH}_{2}\end{array}$ & 0.26 & 0.06 \\
\hline
\end{tabular}

a Reference 7.

b Monocyclization constant in $\mathrm{moldm}^{-3}$.

c Bicyclization constant in $\mathrm{mol} \mathrm{dm}^{-3}$.

sion, the cyclopolymerization of IPA and IPMA proceeds through the monocyclization-bicyclization mechanism proposed for those of VA, VMA, and VCA in the previous paper. ${ }^{7}$

Table III summarizes the parameters of the cyclopolymerization. The most interesting feature is high reactivity of vinyl and isopropenyl groups of a penultimate monomer unit toward a growing polymer radical of VA and IPA. The difference in $r_{\mathrm{c} 1}$ values between VA and IPA suggests that the monocyclization reaction occur's between a growing acryl radical and the $\alpha$-carbon of vinyl or isopropenyl group of a penultimate monomer unit, which leads to the formation of a sixmembered $\gamma$-valerolactone unit. The monocyclization rate of IPA will be lower than that of VA because of steric hindrance of the $\alpha$ methyl substituent in the isopropenyl group. Accordingly, an attack of a growing acryl radical on the $\beta$-carbon of isopropenyl group may participate in the monocyclization reaction, which leads to the formation of a seven-membered $\varepsilon$-caprolactone unit. The absorption band of carbonyl stretching vibration at $1730 \mathrm{~cm}^{-1}$ in the IR spectrum of poly(IPA) indicated the presence of six- and seven-membered lactones along with a linear ester.

Judging from the values of $r_{\mathrm{c} 2}$ for VA and IPA, the bicyclization reaction of the monocyclized radical with the isopropenyl group of a polymer end will give a mixture of sixseven- and seven-seven-membered bicyclic units in addition to six-six-membered bicyclic units. The bicyclic units may increase the stiffness of the polymer chain that causes the ambiguous ${ }^{1} \mathrm{H}$ NMR spectrum of poly(IPA) in carbon tetrachloride.

On the other hand, the $r_{\mathrm{c} 1}$ value for IPMA is comparable to that for VMA. This suggests that the monocyclization reaction is mainly controlled by the $\alpha$-substituent of acryl group and hardly occurs in both polymerizations of IPMA and VM.A. The bicyclization reaction is little affected by the $\alpha$-substituent of acryl as well as vinyl group, and the extent of bicyclization for all of the monomers is low at moderate monomer concentrations.

The polymers will consist of linear, monocyclic, and bicyclic structural units having a molar ratio,

$$
f_{\mathrm{L}}: f_{\mathrm{c} 1}: f_{\mathrm{c} 2}=[\mathrm{M}]_{\mathrm{Q}}\left([\mathrm{M}]_{0}+r_{\mathrm{c} 2}\right): r_{\mathrm{c} 1}: r_{\mathrm{c} 1} r_{\mathrm{c} 2}
$$

where $f_{\mathrm{L}}, f_{\mathrm{c} 1}$, and $f_{\mathrm{c} 2}$ are mole fractions of respective units in the polymers. ${ }^{7}$ The poly(IPA) prepared at $1.0 \mathrm{~mol} \mathrm{dm} \mathrm{dm}^{-3}$ of monomer concentration will consist of $73.7 \%$ of the monocyclic unit and $9.6 \%$ of the bicyclic unit, while the poly(IPMA) will consist of $19.5 \%$ of the monocyclic unit and $1.1 \%$ of the bicyclic unit. 
Effects of Temperature on the Cyclopolymerization of IPA

Polymerization of IPA was carried out at $50-70^{\circ} \mathrm{C}$ in order to see if the cyclization reaction would change. Figure 4 shows the plots of $\log \left(f_{\mathrm{u}} / f_{\mathrm{c}}\right)$ and $\log R_{\mathrm{p}}$ against the reciprocal of absolute temperature. Although the ratio of $f_{\mathrm{u}} / f_{\mathrm{c}}$ is not equal to that of the intermolecular propagation rate over the intramolecular cyclization rate, a difference in apparent activation energy between intramolecular cyclization and intermolecular propagation $\left(E_{\mathrm{c}}-E_{\mathrm{p}}\right)$ can be calculated to be $10.8 \mathrm{~kJ} \mathrm{~mol}^{-1}$ from the slope of the line of $\log \left(f_{\mathrm{u}} / f_{\mathrm{c}}\right)$ vs. $T^{-1}$. This value is comparable to those reported for the cyclopolymerization of symmetrical 1,6-dienes such as acrylic anhydride ${ }^{11}$.and methacrylic anhydride. ${ }^{12}$ The ratio of frequency factors for two steps, $A_{\mathrm{c}} / A_{\mathrm{p}}$, is found to be $49 \mathrm{~mol}$ $\mathrm{dm}^{-3}$ which is one third of that for acrylic anhydride $^{11}$ and one fifth of that for methacrylic anhydride. ${ }^{12}$.This still suggests that an enhanced reactivity of the pendent isopropenyl group of a penultimate monomer unit toward a growing polymer radical is brought about by a larger frequency factor of intramolecular cyclization as compared to that of intermolecular propagation.

The apparent activation energy for the overall rate of polymerization of IPA is calculated to be $96.4 \mathrm{~kJ} \mathrm{~mol}^{-1}$ from the slope of the line of $\log R_{\mathrm{p}}$ vs. $T^{-1}$. This value suggests that the polymerization of IPA proceeds through the usual process as that of acryl monoolefins except for the intramolecular cyclization.

\section{Copolymerization with Styrene}

Both IPA and IPMA were copolymerized with styrene $(\mathrm{St})$ under the same conditions as homopolymerization. Figure 5 shows copolymer composition as a function of composition of feed monomers and Table IV summarizes the results of the copolymerizations. Fineman-Ross plots gave apparent mono-

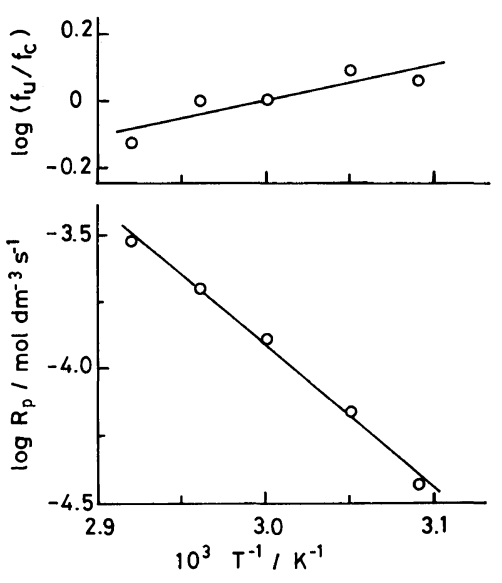

Figure 4. Effects of temperature on the overall rate of polymerization of IPA and on the degree of cyclization $f_{\mathrm{c}}$ $\left(=1-f_{\mathrm{u}}\right):[\mathrm{IPA}]_{0}, 1.0 \mathrm{~mol} \mathrm{dm}^{-3} ;[\mathrm{AIBN}]_{0}, 0.010 \mathrm{~mol}$ $\mathrm{dm}^{-3}$.

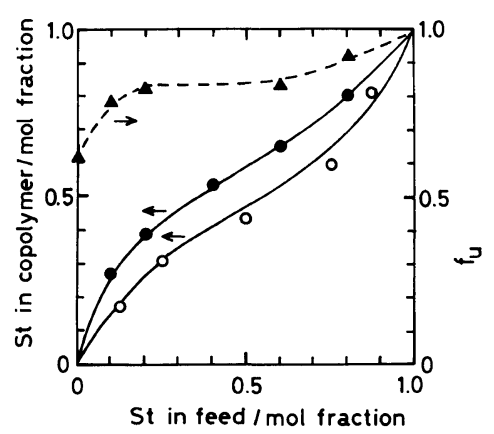

Figure 5. Composition and the fraction of residual isopropenyl groups per IPA monomer unit of copolymer, $f_{\mathrm{u}}$, as a function of composition of monomer feed: , $\Delta$, St-IPA; O, St-IPMA; $[\mathrm{M}]_{0}, 2.0 \mathrm{~mol} \mathrm{dm}^{-3}$; $[\mathrm{AIBN}]_{0}, 0.010 \mathrm{~mol} \mathrm{dm}^{-3}$; temp, $60^{\circ} \mathrm{C}$; solvent, benzene.

mer reactivity ratios; $r_{1}(\mathrm{St})=0.79, r_{2}(\mathrm{IPA})=$ 0.23 for St-IPA and $r_{1}(\mathrm{St})=0.35, r_{2}(\mathrm{IPMA})=$ 0.60 for St-IPMA. These monomer reactivity ratios are compared to those of St-MA, $r_{1}=0.75, r_{2}=0.18,{ }^{13}$ and St-MMA, $r_{1}=0.52$, $r_{2}=0.46 .{ }^{14}$ In the copolymerization with styrene, IPA is as reactive as MA, while IPMA is more reactive than MMA. In conclusion, the intermolecular propagation will take place mainly between a growing polymer radical and acryl or methacryl group of IPA or IPMA monomer. 
W. FUKUDA et al.

Table IV. Copolymerization of styrene with IPA and IPMA ${ }^{\mathrm{a}}$

\begin{tabular}{|c|c|c|c|c|c|}
\hline $\begin{array}{l}\text { Mole fraction } \\
\text { of St in feed }\end{array}$ & $\frac{\text { Time }}{\min }$ & $\frac{\text { Yield }}{\%}$ & $\frac{\mathrm{C}}{\%}$ & $\frac{\mathrm{H}}{\%}$ & $\begin{array}{l}\text { Mole fraction of } \\
\text { St in copolymer }\end{array}$ \\
\hline \multicolumn{6}{|l|}{ St-IPA } \\
\hline 0.10 & 40 & 5.6 & 71.46 & 7.05 & 0.27 \\
\hline 0.20 & 120 & 12.8 & 74.47 & 7.36 & 0.38 \\
\hline 0.40 & 180 & 14.3 & 78.65 & 7.50 & 0.53 \\
\hline 0.50 & 210 & 15.0 & 81.96 & 7.71 & $0.65\left(0.65^{\mathrm{c}}\right)$ \\
\hline 0.80 & 240 & 13.0 & 86.39 & 7.69 & 0.80 \\
\hline \multicolumn{6}{|l|}{ St-IPMA } \\
\hline 0.13 & 50 & 4.5 & 70.22 & 7.99 & 0.16 \\
\hline 0.25 & 140 & 10.1 & 73.44 & 8.14 & $0.30\left(0.32^{d}\right)$ \\
\hline 0.50 & 100 & 5.4 & 76.48 & 8.04 & 0.43 \\
\hline 0.75 & 240 & 9.8 & 80.61 & 8.02 & 0.59 \\
\hline 0.88 & 140 & 4.8 & 86.65 & 7.82 & 0.81 \\
\hline
\end{tabular}

${ }^{a}$ In benzene at $60^{\circ} \mathrm{C} ;[\mathrm{M}]_{0}, 2.0 \mathrm{~mol} \mathrm{dm}^{-3} ;[\mathrm{AIBN}]_{0}, 0.010 \mathrm{moldm}^{-3}$.

b Determined by carbon content.

c Determined by ${ }^{1} \mathrm{H}$ NMR spectroscopy; mole fraction of isopropenyl groups per IPA unit, $f_{\mathrm{u}}, 0.84$.

${ }^{\mathrm{d}}$ Determined by ${ }^{1} \mathrm{H}$ NMR spectroscopy; mole fraction of isopropenyl groups per IPMA unit, $f_{\mathrm{u}}, 0.86$.

The degree of cyclization of the IPA unit in the copolymer decreased with increasing composition of styrene as shown in Figure 5. This may be interpreted as an increase in the intermolecular propagation to styrene and difficult intramolecular cyclization of the resulting styryl radical with the isopropenyl group of a penultimate monomer unit, since the calculated monomer reactivity ratios of styrene and isopropenyl acetate are $r_{1}(\mathrm{St})=$ 17.5 and $r_{2}$ (isopropenyl acetate) $=0.052$ from their $Q$ and $e$ values. ${ }^{10}$

In conclusion, the radical polymerization of isopropenyl acrylate and methacrylate as unsymmetrical 1,5-dienes give the polymers containing cyclic units larger than six-membered rings through the process of monocyclization between a growing polymer radical and the pendent isopropenyl group of a penultimate monomer unit and bicyclization between a monocyclized radical and the isopropenyl group of a terminal unit.

\section{REFERENCES}

1. J. Roovers and G. Smets, Makromol. Chem., 60, 89
(1963)

2. I. A. Arbuzova and E. N. Rostovskii, J. Polym. Sci., 52, 325 (1961).

3. L. Trossarelli, M. Guaita, and A. Priola, Makromol. Chem., 100, 147 (1967).

4. M. Yamada and I. Takase, Kobunshi Kagaku, 19, 11 (1962); 20, 180 (1963).

5. I. Takase and H. Aida, Polym. Prepr., Jpn., 34, 1294 (1985).

6. W. Fukuda, M. Nakao, K. Okumura, and H. Kakiuchi, J. Polym. Sci., A-1, 10, 237 (1972).

7. W. Fukuda, Y. Yamano, M. Tsuriya, and $\mathrm{H}$. Kakiuchi, Polym. J., 14, 127 (1982).

8. A. N. Nesmeyanov, I. F. Lutsenko, and Z. M. Tumanova, Izv. Akad. Nauk SSSR, Otd. Khim. Nauk, 1949, 601; Chem. Abstr., 44, 7225d (1950).

9. L. S. Luskin, "Vinyl and Diene Monomers," Part 1, E. C. Leonard, Ed., Wiley-Interscience, New York, 1970, p. 188.

10. J. Brandrup and E. H. Immergut, Ed., "Polymer Handbook," 2nd Ed., Wiley-Interscience, New York, 1975, pp II-291, II-402.

11. J. Mercier and G. Smets, J. Polym. Sci., A, 1, 1491 (1963).

12. T. F. Gray, Jr. and G. B. Butler, J. Macromol. Sci., Chem., A9, 45 (1975).

13. K. W. Doak, J. Am. Chem. Soc., 72, 4681 (1950).

14. F. M. Lewis, C. Walling, W. Cummings, E. R. Briggs, and F. R. Mayo, J. Am. Chem. Soc., 70, 1519 (1948). 